It is surprising that, except in Brockman's (1930) monograph, none of the communications on the results of primary management of clubfoot present a statistical analysis. Those surgeons who use the Denis Browne splint or a modification claim to have very gratifying results (Browne, 1937, 1956 ; Bell and Grice, 1944 ; Thomson, 1949). However, in a recent survey by McCauley, Lusskin, and Bromley (1964), these workers stated that: "Because of the development of flat-foot following treatment in some of the patients we question the use of the Denis Browne splint as a corrective device."

In the light of the present findings it is suggested that the numerous modifications which have been devised for the Denis Browne splint (Thomson, 1942, 1949 ; Bell and Grice, 1944) disclose the discontent with the results obtained by its use. There is a paucity of statistical evidence in the literature on the efficiency of the splint. Its virtues are much vaunted, its weaknesses concealed.

The statistics of the present survey on the treatment by stretching and Robert Jones's strapping compare favourably with those of Brockman (1930), who used a similar method: in 73 patients $50.6 \%$ required only manipulation and strapping to cure the deformity ; $20.5 \%$ also had division of the tendo calcaneus with plaster splintage ; $24.6 \%$ were not cured by either of these methods and required some form of open operation; $4.1 \%$ still retained this deformity after all these methods and an operation on bone was performed. His later despondency (Brockman, 1937) was hardly warranted by the quality of his results.

More recently Thomas (1964) claims that $90 \%$ of patients can be cured by simple manipulation followed by splinting, if the baby is treated daily as soon after birth as possible.

The evidence presented here leaves no doubt that the successful treatment of talipes equinovarus must begin at birth.

Though it is not invariably successful, repeated gentle stretching and the application of adhesive strapping to maintain correction is a more satisfactory technique than either the Denis Browne splint or serial plaster-of-Paris casts. We have been too easily persuaded to relinquish Robert Jones's method of treatment, which, apart from its high rate of success, has the merit of simplicity and the additional appeal of being old-fashioned.

\section{Summary}

Three different methods for the primary treatment of congenital clubfoot have been compared. These methods were the Denis Browne splint, stretching and adhesive strapping, and serial plaster-of-Paris casts. There were 140 patients in the series and 221 feet were affected. Only 20 (19\%) of 105 feet were successfully treated by the Denis Browne method alone, whereas 68 feet out of $96(71 \%)$ were treated successfully by stretching and strapping. None of the 20 feet treated by manipulation and serial plaster-of-Paris casts could be regarded as corrected. These results show that splintage alone is of little value for the correction of clubfoot deformity and that correction followed by fixation with adhesive strapping is far more effective.

I owe my gratitude to Mr. G. C. Lloyd-Roberts and Mr. H. H. Nixon for their encouragement and help during this survey of their patients. My thanks are also due to Mr. R. A. Denham, of the Royal Hospital, Portsmouth, for his generosity in allowing me to review the patients under his care.

\section{REFERENCES}

Bell, J. F., and Grice, D. S. (1944). F. Bone ft. Surg., 26, 799. Brockman, E. P. (1930). Congenital Club-Foot. Wright, Bristol. - (1937). Brit. med. 9., 2, 572 .

Browne, D. (1937). Ibid., 2, 570.

- (1956). Clinical Orthopaedics-No. 8. Lippincott, Philadelphia. Elmslie, R. C. (1920). F. orthop. Surg., 28, 668.

Jones, R (1894). Trans. Brit orthop Soc, 120.

and Lovett, R. W. (1929). Orthopaedic Surgery, 2nd ed. Oxford University Press, London.

McCauley, J., Lusskin, R., and Bromley, J. (1964). F. Bone ft. Surg. 46A, 525 .

Thomas, G. E. (1964). Ibid., 46B, 792.

Thomson, S. A. (1942). Ibid., 24, 291.

(1949). Ibid., 31A, 431.

\title{
Hepatic Dysfunction in the Congenital Rubella Syndrome
}

\author{
GILLES R. G. MONIF,* M.D. ; RICHARD ASOFSKY,* M.D. ; JOHN L. SEVER,* M.D., PH.D.
}

Brit. med. F., 1966, 1, 1086-1088

The congenital rubella syndrome once defined a morphologically static condition: specific malformations which were the sequelae of maternal infection with rubella virus early in gestation. It is now apparent that this term is conceptually limited, and must be expanded to include an "acute" component due to continued virus action in the neonatal period and beyond (Alford et al., 1964 ; Monif et al., 1965). Thrombocytopenia, encephalitis, interstitial pneumonia, myocardial injury, and hepatitis have all recently been described in infants with the rubella syndrome (Rudolph et al., 1965 ; Korones et al., 1965 ; Hardy et al., 1966). It is the purpose of this paper to characterize the hepatitis more completely.

\section{Materials and Methods}

Six cases of congenital rubella syndrome, confirmed by virus isolation from either throat or urine specimens, were identified in which, in addition to the classical stigmata of the rubella syndrome, there was evidence of hepatic dysfunction. Two of the six infants with biochemical evidence of hepatic dysfunction came to necropsy. In addition to the review of the clinical data and histological analysis, the livers from these two infants and a percutaneous liver biopsy specimen from a third infant were studied for the recovery of virus.

The two livers were homogenized in Hanks's balanced salt solution containing penicillin, 400 units $/ \mathrm{ml}$., and streptomycin, $0.4 \mathrm{mg} . / \mathrm{ml}$; ; and then the homogenate was diluted to a $20 \%$ suspension. Each specimen was then centrifuged at $600 \mathrm{~g}$. for 15 minutes, and $0.2-\mathrm{ml}$. aliquots of the supernatant were inoculated into four primary African green monkey kidney cultures in roller tubes. The cultures were maintained with $1.5 \mathrm{ml}$. of medium consisting of Eagle's basal medium con-

* From the Section on Infectious Diseases, Perinatal Research Branch, National Institute of Neurological Diseases and Blindness, and the National Institute of Neurological Diseases and Blindness, and the Laboratory of Infectious Diseases, National Institutes of Allergy and Maryland. 
taining antibiotics and $0.2 \% \mathrm{SV}-5$ rabbit antisera according to the procedures previously described (Sever et al., 1962). The cultures were incubated at $37^{\circ} \mathrm{C}$. in a stationary position for eight days, at which time the medium was removed and fresh medium added. Two tissue cultures of each set of four tubes were inoculated 24 hours later with 100 TCID $_{50}$ of Coxsackie A-9. The remaining two cultures were allowed to incubate for an additional four days, after which $0.2 \mathrm{ml} . /$ tube of the fluid and cells were inoculated into four additional primary African green monkey kidney cultures. The challenge consisted of 100 TCID $_{50}$ of Coxsackie A-9, injected eight days later into each of these two tubes. All specimens were carried in this manner through three passages.

Interference with the cytopathic effect seen with Coxsackie A-9 was interpreted as suggesting the presence of rubella virus. Interfering agents were identified by neutralization with specific rubella antiserum in primary African green monkey kidney cultures, utilizing the method previously reported (Schiff, et al., 1963). The fragments of liver obtained by percutaneous punch biopsy were tensed out with glass needles and then placed directly on to a sheet of primary African green monkey kidney

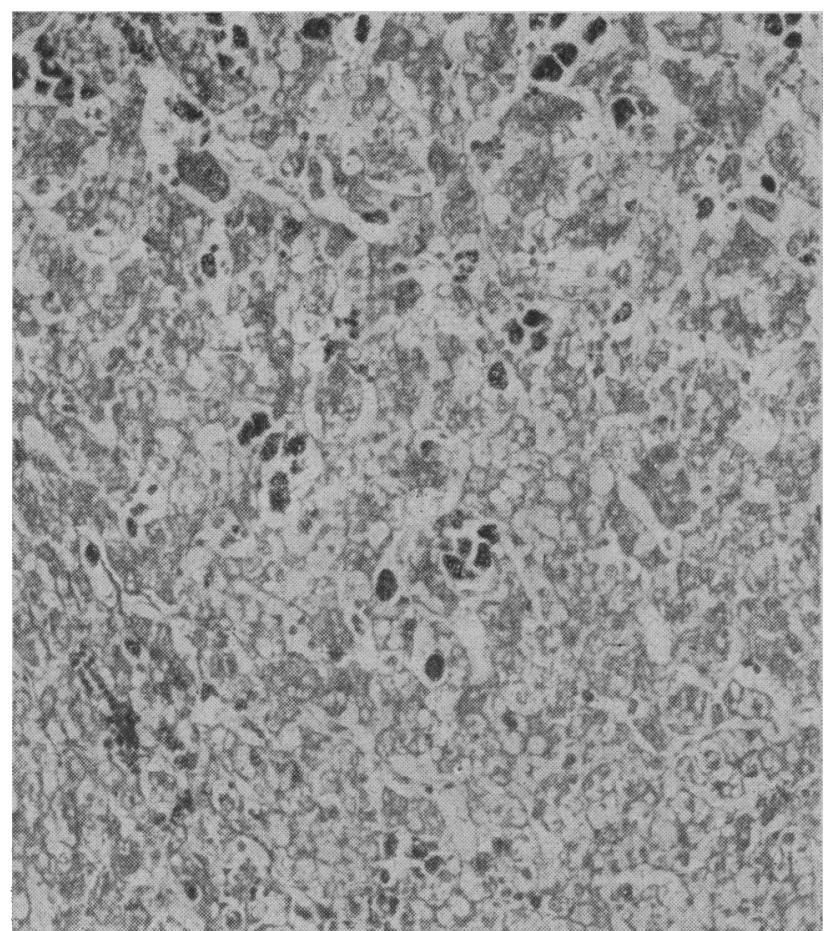

Fig. 1.-Swollen Kupffer cells engorged with bile pigment. (H. and E. $\times 160$. cells. After seven days $0.2 \mathrm{ml}$./tube of the fluid and cells were inoculated into four primary African green monkey kidney culture roller tubes. The subsequent handling of these cultures was as described above.

\section{Results}

Hepatic Function.-The clinical and biochemical data for the six cases are summarized in the Table. Jaundice was noted within the first 24 hours in three cases, and in all cases within 48 hours. The livers were palpable $3-5 \mathrm{~cm}$. and the spleens $1-5 \mathrm{~cm}$. below the costal margin. Hepatosplenomegaly persisted during the period of overt hepatic dysfunction. Clay-coloured stools were observed for Cases 1 and 6. After preliminary studies had excluded $\mathrm{Rh}-\mathrm{ABO}$ incompatibilities, neonatal sepsis, congenital syphilis, toxoplasmosis, systemic herpetic infection, and, in Cases 1, 3, and 4, infection with salivary-gland virus, the clinical diagnosis was congenital biliary atresia or hepatitis of unknown aetiology.

Histology.-The livers ${ }^{1}$ in Cases 4 and 5 were similar. The most striking feature was swelling and engorgement of the

' In both cases careful dissection of the extrahepatic biliary ducts had, according to the available protocols, failed to demonstrate gross evidence of obstruction.

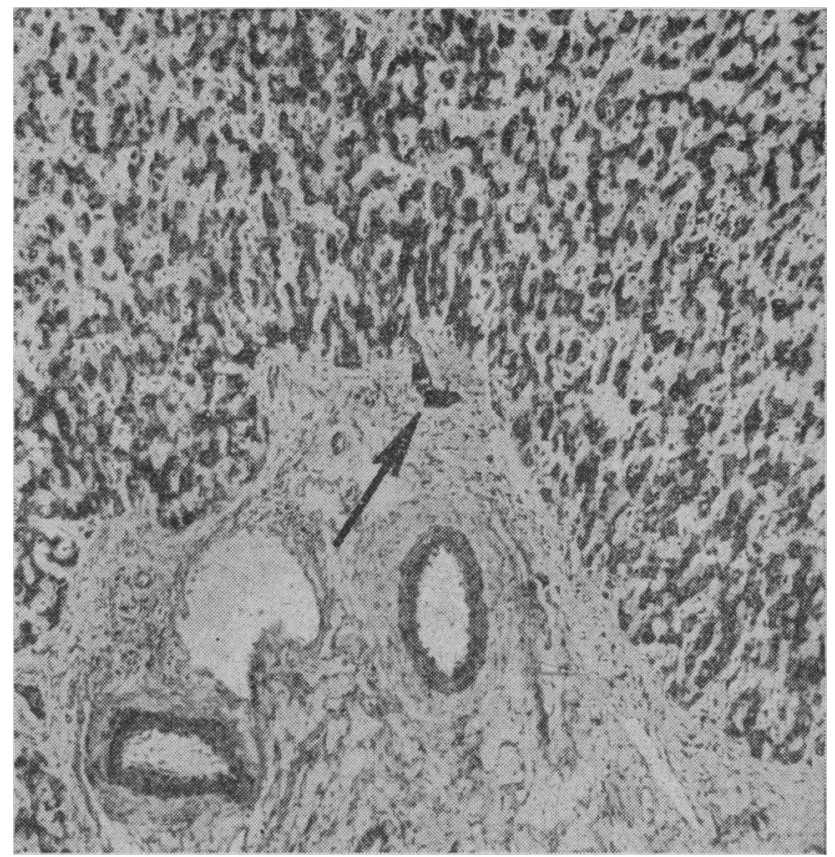

FIG. 2.-Ductular bile stasis. (H. and E. $\times$ 63.)

\begin{tabular}{|c|c|c|c|c|c|c|c|c|}
\hline & & & Case 1 & Case 2 & Case 3 & Case 4 & Case 5 & Case 6 \\
\hline Days $1-4$ & . & . & - & $\begin{array}{l}\text { Total bilirubin } 24(2) * \text {, } \\
19(3)\end{array}$ & $\underset{17 \cdot 3 / 7 \cdot 5(3)}{\text { Bilirubin }} 7 \cdot 6 / 2 \cdot 7$ (1) & $\begin{array}{l}\text { S.G.O.T. } 82(4) ; \\
\text { S.G.P.T. } 57(4)\end{array}$ & $\begin{array}{l}t(1) ; \text { total bilirubin } \\
8.0(2), 10.0(4)\end{array}$ & $\begin{array}{l}\text { Total bilirubin } 10.0(1) \\
7 \cdot 8 / 5 \cdot 0(3) ; \text { alk. } \\
\text { ptase. 18.4(3); } \\
\text { S.G.O.T.130; }\end{array}$ \\
\hline Days 5-7 & . & .. & Bilirubin $10 \cdot 2 / 5 \cdot 8(7)$ & Bilirubin $6 \cdot 8 / 4 \cdot 0(5)$ & Bilirubin $14 \cdot 5 / 5 \cdot 1$ (6) & $\underset{10 \cdot 8 / 3 \cdot 0(7)}{\operatorname{Bilirubin}} 11 \cdot 8 / 2 \cdot 2(6)$, & Total bilirubin $9.6(5)$ & Total bilirubin $14 \cdot 4$ (6) \\
\hline Second wee & & $\cdots$ & - & - & Bilirubin 8.9/4.6 & Bilirubin $7 \cdot 2 / 2 \cdot 6$; & Bilirubin 4.6/4.6 & Bilirubin $8 \cdot 3 / 5 \cdot 8$; \\
\hline Third , & . & . & 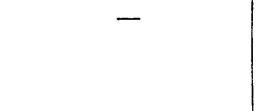 & $\begin{array}{l}\text { Bilirubin } 2 \cdot 9 / 0 \cdot 9 \text {; } \\
\text { S.G.O.T. } 56 \text {; C.F. } \\
\text { neg.; prothrombin } \\
\text { time normal }\end{array}$ & $\begin{array}{l}\text { Total bilirubin } 5.3 \text {; } \\
\text { S.G.O.T. } 141 \text {; } \\
\text { S.G.P.T. } 67 \text {; chol- } \\
\text { esterol } 250 \text {; T.S.P. } \\
\text { 6.7 (A/G } 3.3 / 3.4)\end{array}$ & Bilirubin $5 \cdot 3 / 3 \cdot 1$ & $\begin{array}{l}\text { Bilirubin 4.0/5.3, 4.3/ } \\
4 \cdot 6 \text {; S.G.O.T. 760, } \\
640 \text { S.G.P.T. } 400, \\
270 ; \text { T.S.P. } 5 \cdot 9 \\
\text { (A/G 3.8/2.1) }\end{array}$ & $\begin{array}{l}\text { Bilirubin } 4 \cdot 5 / 2 \cdot 2 \text {; C.F. } \\
\quad+2 \text {; S.G.O.T. } 320\end{array}$ \\
\hline Fourth," & .. & . & $\begin{array}{l}\text { Bilirubin } 6 \cdot 1 / 5 \cdot 9 ; \\
\text { S.G.O.T. } 89,170 ; \\
\text { C.F. }+2 . T . T \text { neg. }\end{array}$ & C.F. neg. & & Bilirubin 4.5/1.5 & & $\begin{array}{l}\text { Bilirubin } 4 \cdot 0 / 2 \cdot 2 \text {; } \\
\text { S.G.O.T. } 92\end{array}$ \\
\hline \multicolumn{3}{|c|}{ Final determination } & $\begin{array}{c}\text { Bilirubin } 5 \cdot 7 / 5 \cdot 5 \text { (57 } \\
\text { days); prothrombin } \\
\text { time normal ; rubella } \\
\text { virus recovered from } \\
\text { liver biopsy ( } 65 \text { days) }\end{array}$ & $\begin{array}{r}\text { Total bilirubin 0.4 (69 } \\
\text { days); S.G.O.T. } 49\end{array}$ & $\begin{array}{r}\text { (Non-icteric at time of } \\
\text { discharge-39 days) }\end{array}$ & $\begin{array}{l}\text { (Died on } 31 \text { st day of } \\
\text { life.) Rubella virus } \\
\text { recovered from liver }\end{array}$ & $\begin{array}{l}\text { (Died on 22nd day of } \\
\text { life.) Rubella virus } \\
\text { recovered from liver }\end{array}$ & $\begin{array}{l}\text { Bilirubin } 1 \cdot 8 / 0 \cdot 9 ; \\
\text { S.G.O.T. 70; C.F } \\
\quad+2 \text { (28th day) }\end{array}$ \\
\hline
\end{tabular}


Kupffer cells with green pigment (Fig. 1). This was most prominent in areas of apparent drop-out of parenchymal cells. The pigment ranged from finely to very coarsely granular. It gave a positive Stein test and a negative Gmelin reaction; it stained with methylene blue but not with iron stains, and did not fluoresce. There were, in addition, foci of canalicular and ductular bile stasis (Fig. 2). Bile ductules were apparently reduced in number. Zones of haematopoeisis were present in both livers; in Case 5 there were many blast-like cells in these areas. There was a slight increase in periportal fibrous tissue in both cases.

Virology.-Three livers were studied for the presence of rubella virus. Recovery and specific identification of the virus was achieved in all three of the cases studied.

\section{Comment}

While the biochemical changes were primarily related to elevations of indirect bilirubin, abnormally high values for the transaminases were recorded in Cases 5 and 6 . Late in the course of the disease there was a reversal of the albuminglobulin ratio in Case 3.

Two clinical patterns were present. Either there was gradual biochemical and clinical amelioration to normal values and status, or a chronic indolent course was pursued associated with persistent jaundice and biochemical derangement. The livers at necropsy in Cases 4 and 5 revealed the histological corollary of this latter clinical observation when observed at 22 and 34 days of age. The presence of increased periportai fibrous tissue which extends into the lobules at 34 days suggests that this process may progress and indeed be one of the aetiologies for juvenile cirrhosis. Almost equally important are the percutaneous liver biopsy specimens obtained in Cases 2 and 6, which revealed normal hepatic architecture coinciding with the return to normal of biochemical indices measuring liver function (F. Fuste, personal communication, 1965). With respect to the unusual histological picture, it is noteworthy that Beard (1956) described a very similar finding in what appears to be a case of transplacental hepatitis except that Beard reported considerably more necrosis than we have observed.

The infants cited (Cases 1-6) were the products of full-term pregnancies with a range of 38-41 weeks' gestation. Cases 1 , 2 , and 4 weighed less than $2,500 \mathrm{~g}$. The presence of marked bilirubin elevation on the first or second day of life indicated an abnormal event superimposed on prematurity. The serum glutamine oxaloacetic transaminase (S.G.O.T.) in Cases 5 and 6 was abnormally. elevated. However, the differential diagnosis was complicated owing to the haemolytic process associated with the rubella syndrome (Zinkham and Medearis, 1966). Nucleated red cells and reticulocytosis were present in Cases 2 and 4. Serial haematocrit readings for both groups were invariably at the lower limits of normal values for a given age. Additional evidence of haemolysis was furnished by the continued erythropoiesis in lung, liver, and spleen well beyond that time when it normally disappears. These findings are present in most cases of the congenital rubella syndrome (Korones et al., 1965 ; Hardy et al., 1966) ; and unpublished data). The critical anatomical and biochemical differentiation was between haemolytic disease of the newborn associated with prolonged "obstructive jaundice" and a cholangitic type of hepatitis of viral origin. While Zuelzer and Brown (1961) have observed normally elevated S.G.O.T. values in the former condition, the early elevation of these values in Case 6 suggests that they were the result of the aetiological process rather than the consequence of a secondary effect.

Rubella virus was isolated from the liver when there was biochemical and/or histological evidence of dysfunction. This was in contrast to our past experience with three rubella syndrome infants who died in the newborn period (Monif et al., 1965). In these cases virus was recovered from only one of five livers studied, and there was no evidence of biochemical or histological hepatic dysfunction. The incidence of recovery of rubella virus from livers with apparent derangement when coupled with a characteristic histological picture favours the hypothesis that this is a hepatitis of viral origin.

\section{Summary}

Six cases are described in which hepatic dysfunction was associated with the classical finding of the congenital rubella syndrome. Necropsy liver specimens and a liver biopsy from three of these cases when studied by histological and virus isolation techniques revealed a correlation between hepatic derangement and recovery of the virus. One of the cases at necropsy had histological changes suggestive of early cirrhosis.

We are indebted to Drs. Marvin Kuschner and Leon Sokoloff for their review of the histological material and for their constructive criticism. A debt of gratitude must be expressed to Drs. Sheldon B. Korones, Gordon B. Avery, and Janet Hardy for making this study possible; to Drs. F. Fuste, D. Kamala, and B. Ruebner for supplying tissue blocks for histological sections; and to Betty J. Sanders and Barbara G. Mance for technical assistance.

\section{REFERENCES}

Alford, C. A., Neva, F. A., and Weller, T. H. (1964). New Engl. F. Med., 271, 1275 .

Monif, G. R. G., Avery, G. B., Korones, S. B., and Sever, J. L. (1965). Lancet, 1,723 .

Hardy, J. B., and Sever, J. L. (1966). Bull. Fohns Hopk. Hosp., 118, 85 .

Rudolph, A. J., Yow, M. D., Phillips, C. A., Desmond, M. M., Blattner, R. J., and Melnick, J. L. (1965). F. Amer. med. Ass., 191, 843.

Korones, S. B., Ainger, L. E., Monif, G. R. G., Roane, J., Sever, J. L., and Fuste, F. (1965). F. Pediat., 67, 166.

Schiff, G. M., Sever, J. L., and Huebner, R. J. (1963). Science, 142, 58. Sever, J. L., Schiff, G. M., and Traub, R. G. (1962). F. Amer. med. Ass., $182,663$.

Beard, A. G. (1956). F. Pediat., 49, 454.

Zinkham, W. H., and Medearis, D. N. (1966). F. Pediat. In press.

Zuelzer, W. W., and Brown, A. K. (1961). Amer. F. Dis. Child., 101, 87. 